\title{
Photovoltaic road and rail noise barriers at different environmental and soil conditions, including mining terrains
}

\author{
Kurt Fallast $^{1}$, Maria Hadjipanayi ${ }^{2}$, Pawet Kwaśnicki ${ }^{3}$, Zbigniew Motyka ${ }^{4, *}$, Emilio Muñoz \\ Cerón ${ }^{5}$ \\ ${ }^{1}$ IBV-Fallast, Graz, Austria \\ ${ }^{2}$ University of Cyprus, Nicosia, Cyprus \\ ${ }^{3}$ ML System S.A., Zaczernie, Poland \\ ${ }^{4}$ Główny Instytut Górnictwa, Katowice, Poland \\ ${ }^{5}$ University of Jaén, Jaén, Spain
}

\begin{abstract}
Regulations and standards concerning noise road and rail barriers are presented together with an actual state-of-the-art in Europe. Application of photovoltaics to such infrastructure are considered. The targets of international CEFRABID research project, realised within ERA-SOLAR.NET European program, and concerning photovoltaic road and rail noise barriers for Austria, Cyprus, Poland and Spain, at different environmental and soil conditions, including mining terrains are shortly presented.
\end{abstract}

Keywords: road and rail noise barier, photovoltaics, mining areas, seismicity, environmental conditions, European standards

\section{Introduction}

While designing noise road and rail barriers in urbanized industrial areas, especially those covered by the ongoing or past mining activities, we need to consider the adverse effects of such activities on surface infrastructure. The objective of the study presented herein is to develop basis for realization targets of international CEFRABID research project, realized within ERA-SOLAR.NET European program, and concerning development of hybrid photovoltaic road and rail noise barriers designs suitable for Austria, Cyprus, Poland and Spain, in aims of obtaining necessary characteristics of future infrastructure designed for different environmental and ground conditions, including seismic terrains, as well as the ones with underground mining activities, containing hybrid

* Corresponding author: zmotyka@gig.eu 
photovoltaic noise road and rail barriers. To assure this objectives an analysis of regulations and standards concerning noise road and rail barriers is presented together with an actual general state-of-the-art in Europe.

\section{Regulations \& standards}

There were many activities in Europe concerning road and rail noise barriers.

Noise is an important factor to be considered when it comes to developing, upgrading and maintaining national highway networks in Europe. Significant financial resources are used to incorporate noise abatement measures in developing or upgrading national highways. There are known methods and strategies for assessing and addressing noise impacts. In particular noise abatement planning for different acoustic barrier designs, e.g., in [1] Danish and some other European countries examples of serious activities were undertaken in relation to the improvement and enlarge existing structure. The European noise group from the Conference of European Directors of Roads (CEDR) developed 14 recommendations to National Road Administrations (NRA) for good governance regarding noise management and abatement. With regards to design and maintenance of noise barriers, it was noted that [2]:

- When planning to incorporate noise abatement measures on new, existing and reconstructed roads, it is important to adopt a time horizon of 20 to 30 years, when predicting future noise from increasing traffic volumes and planning noise measures. This will enhance the robustness of specific noise projects.

- Noise barriers erected on roads have not only visual impacts for the residents living in close proximity to the road but also the driver and their passengers. It is therefore, important to use barrier designs that are appropriate to the specific location where they are installed.

A comprehensive pan-European survey was carried out by CEDR noise group on how noise issues are treated in the European national road administrations (NRAs) [2]. An assessment of noise mitigation measures was undertaken in order to ascertain the most prominent types of mitigation measures used to reduce noise levels on existing and new national road schemes. Survey revealed that noise barriers are by far the most widely used road traffic noise mitigation tool on both existing and new road schemes. The survey revealed that CEDR member states have very different approaches in this area and there appears to be no consistent pattern in their use. $75 \%$ of CEDR member states have some form of national technical standards for the acoustic and nonacoustic properties of noise barriers. Where member states do not have national technical standards, it would appear that noise barriers are then constructed in accordance with the specifications outlined in the European Standards EN 1793 [3, 4, 5, 6, 7] and 1794 [8, 9]. Of the CEDR member states that responded to this question, $90 \%$ have incorporated these European standards into national standards.

To meet structural design and not only acoustic function requirements, other specific standards should be taken into account as well - among others EN 14388 [10], 14389 [1112]. Umbrella standard EN 14388 [10] gives general principles, EN 14389-1 [11] refers control of the acoustic performance of the noise barrier each 5 year period up to 20 years' service. And EN 14389-2 [12] concerns assessing their general durability. Therefore to meet both the structural design and acoustic function requirements, also during their working life the mentioned standards referring to intrinsic acoustic properties EN 1793 [37], to the stability and mechanical requirements 1794 [10-11], and others like eg. EN 14388 [10], 14389 [11-12] should be concerned at conducting their performance tests. First few standards of EN 1793 group are laboratory tests using classical reverberation chambers. 
The rest concerns in-situ test methods and can be applied in-situ for barriers' sections installed in outdoor environmental conditions. EN 1794 [10-11] covers other than acoustic mechanical and structural performance of the of barrier elements. Whilst the purpose of the noise barrier is noise reduction, also its longevity, environmental as well as safety requirements are also of vital importance, and the latter covers EN 1794-1 [10] and EN 1794-2 [5]. The first one refers to calculation and test of such factors as static load and wind load, self weight, impacting of stones, safety in the case of collision and dynamic load during snow clearance. The second one covers calculation and test of such factors as brushwood fire resistance, falling debris danger, environmental protection, escape means, reflection of light and transparency.

Umbrella standard EN 14388 [10] gives general principles. Although HA66/95 [13] requires a 40 year operational life for new built barriers, many of them fail already after 5 10 years, what is the result of poor quality of their construction. For the method of the long term performance assessing of both non-acoustic and acoustic characteristics of a projected noise barrier the standards EN 14389 [11-12] can be used concerning the durability of the noise barrier product. The EN 14389-1 [11] also provides a method of re-test in situ an existing barrier, to determine its actual performance and remaining operational life. The EN 14389-2 [12] provides a metod for assessing non-acoustic aspects of durability (climatic conditions, special climatic conditions, biological conditions, chemically active substances, mechanical conditions). Such assessment of long term performance is used in Germany for many years, so there can be used best known practice.

\subsection{EN 1793-5:2016}

EN 1793-5:2016 assures in situ assessment of values of sound reflection and airborne sound insulation. It says how to perform test in situ or on barriers purposely built to be tested for product qualification. It was compared with EN 1793-2 at [28].

At least 4 meters long and 4 meters high (including fixings and posts installed and as at normal exploitation conditions) section of barrier is needed for performing these tests (Fig.1). As a result sound reflection DLRI index (absorption) and sound insulation index $\mathrm{DL}_{\mathrm{SI}}$ are obtained (Fig.1a).

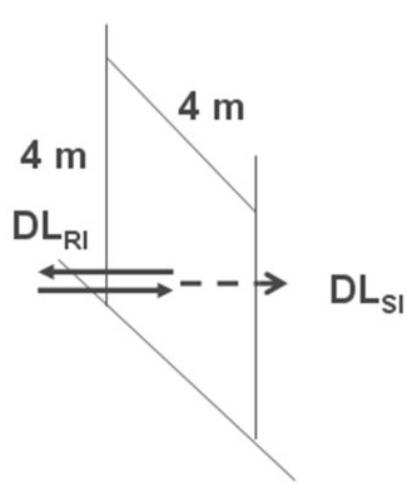

(a)

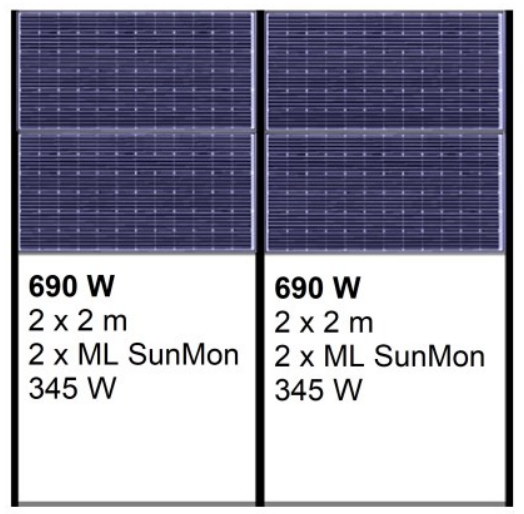

(b)

Fig. 1. Conditions for testing noise screen according to the standard: a) generous layout; b) possible configuration with suggested replacement of traditional filling with 4 PV panels of dimensions $1 \times 2 \mathrm{~m}$. 


\subsection{EN 1793-6: 2018}

EN 1793-6: 2018 "Road traffic noise reducing devices. Test method for determining the acoustic performance - Part 6", describes basic properties, effectiveness of insulation from airborne sound in situ sound conditions, and a method of testing the sound reduction index of devices reducing airborne noise, allowing:

- determination of the acoustic insulation devices performance to be installed along the road for noise reduction, measured in laboratory or in situ conditions;

- determining in situ the characteristics of acoustic insulation by the noise reducing devices during use;

- comparison of specifications of the design with actual data obtained after completion of construction works;

- verification of long-term performance indicators of noise reducing devices (via repeated use of the method);

- in interactive processes of designing new products, including the development of installation manuals.

The results are being expressed as a frequency function in the $1 / 3$ octave band and if possible in the range between 100 and $5000 \mathrm{~Hz}$. When it is not possible to obtain the correct measurement results in the entire frequency range, there is enough to provide them in a limited frequency range, along with reasons for such a restriction.

\section{Noise road barriers actual state-of-the-art}

The relevant researches reveals that over 12 million EU inhabitants are affected by railway noise during the day and 9 million during the night [15]. Because of that railway noise was included as a part of EU Greening Transport Package which was demonstrated in the communication on rail noise abatement measures addressing the existing fleet [14]. The reduction of railway noise can be achieved by three essential types of measures: on the vehicles, on the tracks or in the sound propagation path. In the past years the latter type of measures was most common and noise barriers are the most frequently applied noise abatement measure applied in the propagation path [16]. They are applied on a wide scale both on existing and new lines. Typical noise reductions are up to $10 \mathrm{~dB}$ depending on the barrier height, distance to source and receiver, and barrier absorption. Barrier performance is best if the barrier is close to the source or to the receiver. Noise barriers are generally less cost effective than noise control measures at the source which has been demonstrated in e.g. the STAIRRS project [17].

According to UIC report the construction of noise barriers has still continued during the past years. Several countries have dedicated programmes focusing on this issue (e.g. Germany, Switzerland and France). By the end of 2005 in Europe $1.000 \mathrm{~km}$ of noise barriers were constructed. An estimated total $€ 150-200$ million is spent annually on noise barriers and insulated windows [18]. And these numbers significantly increased in the meantime [19].

The EP and UC Directive of June 2000 on assessment and management of environmental noise, states, that acoustic maps have to be prepared for all main roads, main railroads and main airports, as well as of agglomerations above 100 thousand inhabitants. They also have to be actualised every 5 years.

\subsection{The (partially) transparent reflecting barriers}

Transparent reflecting barriers, made of various polycarbonate and acrylic glass variants are being used together with the absorbing ones, thereby giving the lightness to the latter. 
Individually, they are utilized in the highly urbanized locations. Very often, even a small number of transparent barriers makes a visual success of the object constructed. In particular, this relates to the considerably high barriers located in urban areas. Acoustic barriers, similarly as any other part of the road infrastructure, needs providing the operational care, in the form of current repairs caused by road accidents or acts of vandalism. However, the principal thing is washing and cleaning them after the winter season. Tu sum up, there is a large variety of means and tools in the hands of designers and manufacturers of acoustic barriers, which allow to design and construct human-friendly acoustic barriers, from the visual point of view [20].

Theoretically, the noise barrier is efficient when the difference is higher than zero. However, in practice, when $\Delta \mathrm{L}_{\mathrm{A}}$ is less than $4 \mathrm{~dB}$, the screen is considered ineffective. The effectiveness is satisfactory in the case when $\Delta \mathrm{L}_{\mathrm{A}}$ is higher than $6 \mathrm{~dB}$. But, even in the case when there is a technical possibility of making a barrier with predicted effectiveness, it often proves that the barrier designed becomes a disadvantageous element of architecture, or do not ensure transmission of light. Sometimes, it happens that improperly designed barriers overshadow the properties located close to them. In addition, they may potentially affect the sight to the drivers. This can be solved through using either transparent acoustic barriers, or making ones that contain transparent fragments of glass, acrylic or polycarbonate (PC). PC and acrylic are materials material frequently used for the transparent noise barriers. Acrylic is polymethyl methacrylate (PMMA). "Plexiglass" is a brand of acrylic (PMMA). Acrylite, Plexiglas ${ }^{\circledR}$, Lucite ${ }^{\circledR}$ and Perspex ${ }^{\circledR}$ are brands of acrylic (PMMA). Glass does not have many disadvantages of these materials. E.g., as opposite to acrylic plate, glass-made barriers do not need crosswise reinforcement of glass plate edge, owing to high physicalmechanical characteristics of glass. Glass-made road noise-isolating barriers are built using the laminated non-chipping glass type VSG (Verbund Sicherheits Glas) produced from thermally reinforced TVG (Teilvorge spanntes glas), that is glass mid-hardened with ground edge. This is a high-mechanical strength glass, composed of at least two plates with the thickness not less than $2 \times 8 \mathrm{~mm}$, combined with PVB (Poli-Vinyl-Butyral) foil. Their applicability includes a possibility of using modern solutions (built-in photovoltaic modules, armoured, and overhear panes, etc.), use of panes with self-cleaning cover to protect the main façade against dirt. The advantages of glass acoustic barriers are: perfect visibility, system modularity, high stiffness of elements, durability and corrosion-resistance, as well as resistance to solar radiation [20].

Theoretically, the noise barrier is efficient when the difference at sound transmission with and without barrier is higher than zero. However, in practice, when DL $\alpha$ is less than 4 $\mathrm{dB}$, the screen is considered ineffective. The effectiveness is satisfactory in the case when DL $\alpha$ is higher than $6 \mathrm{~dB}$. But, even in the case when there is a technical possibility of making a barrier with predicted effectiveness, it often proves that the barrier designed becomes a disadvantageous element of architecture, or do not ensure transmission of light. Sometimes, it happens that improperly designed barriers overshadow the properties located close to the them. In addition, they may potentially affect the sight to the drivers. This can be solved through using either transparent acoustic barriers, or making ones that contain transparent fragments.

\subsection{Sound absorbance barriers}

Also railways noise barriers are still more common throughout the Europe. Their construction concentrates mainly on reduction of noise by absorbance of sound. While the road acoustic barriers are mostly sound reflective noise barriers, the ones dedicated to railways are sound absorbance barriers. 
They may be manufactured also in combination with common reflectance barriers. In the case of railways they may be relatively lower, as there is possibility to move them extremely close to rails, as well as due to possibility of neglecting the higher situated engine noise sources (in comparison with these dominating, caused by the rolling of the steel wheel on the steel rails, i.e. railway rolling noise).

\section{CEFRABID project and photovoltaic noise road and rail barriers}

All over Europe for many years experimenatl installations aimed at merging PV panels with road noise barriers are being tested. Fig.2 presents PV application solution in road noise barrier at Gleisdorf, Austria.

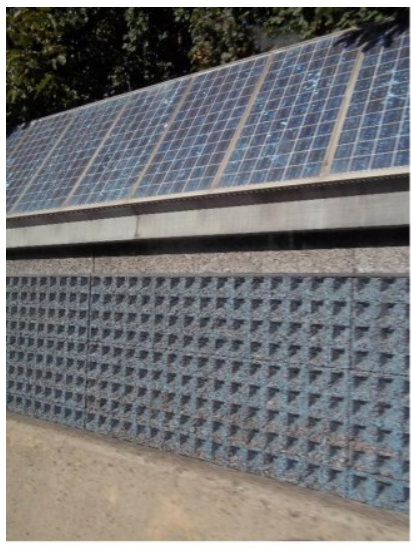

(a)

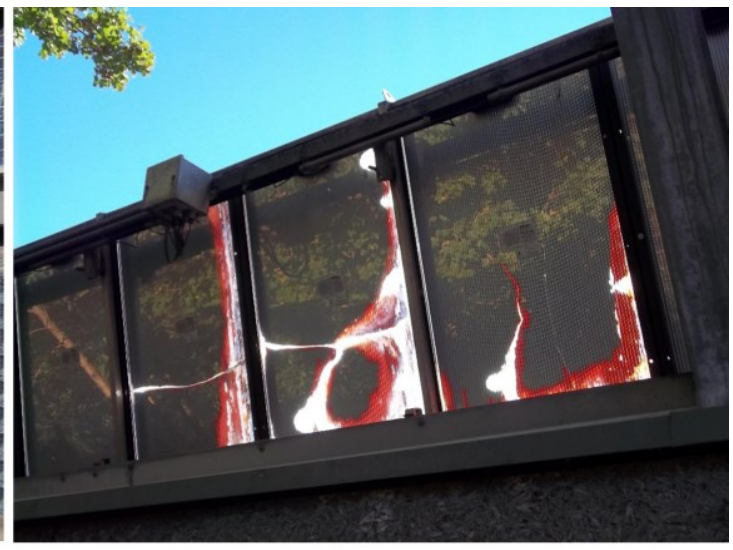

(b)

Fig. 2. Road noise barriers using PV panels - Austria (a) and their deterioration due to heavy exploitation conditions (b)

Fig.3 presents working session panel during one of recent such project's 1st CEFRABID International Conference in Graz, where different possible technical solutions of applying and testing PV panels for noise and rail barriers were discussed. The 2-year long Project is currently running and will end in 2020.

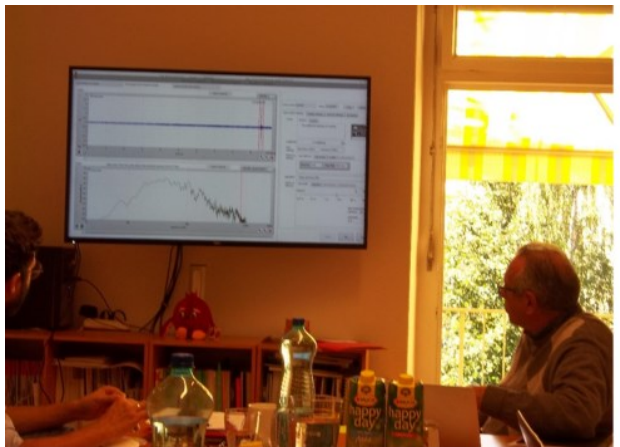

(a)

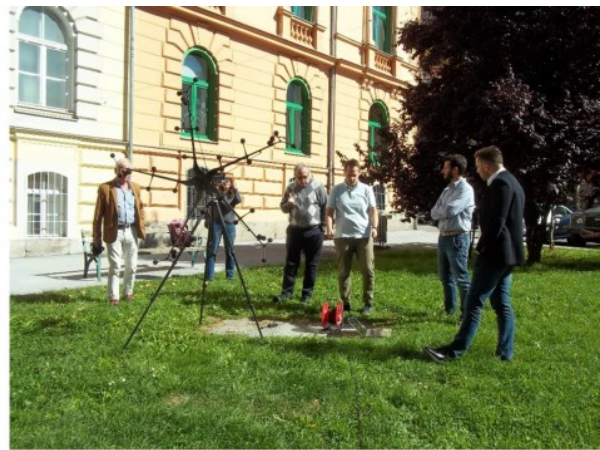

(b)

Fig. 3. Working session panel during 1st CEFRABID International Conference in Graz (a) and presentation of IBV sound beamforming camera (b). 
The CEFRABID project is realised within ERA-SOLAR.NET European program, and its focus are photovoltaic road and rail noise barriers for Austria, Cyprus, Poland and Spain, suitable at different environmental and soil conditions, including mining and seismic terrains.

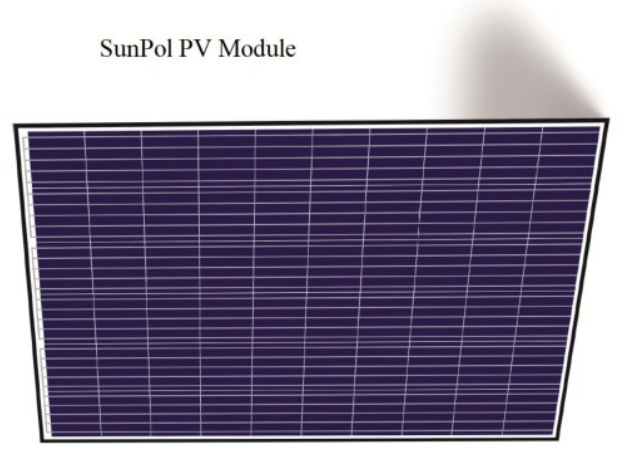

(a)

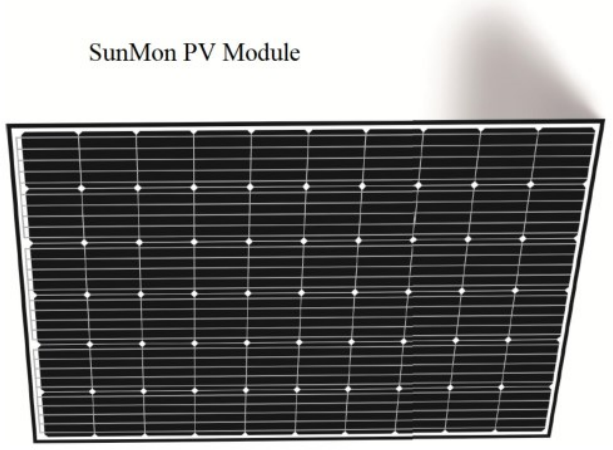

(b)

Fig. 4. PV silica panels which can serve as one of a basis solutions for fulfillment of road and rail noise barriers of dimensions 1 × $2 \mathrm{~m}$ : a) polycrystaline; b) monocrystaline.

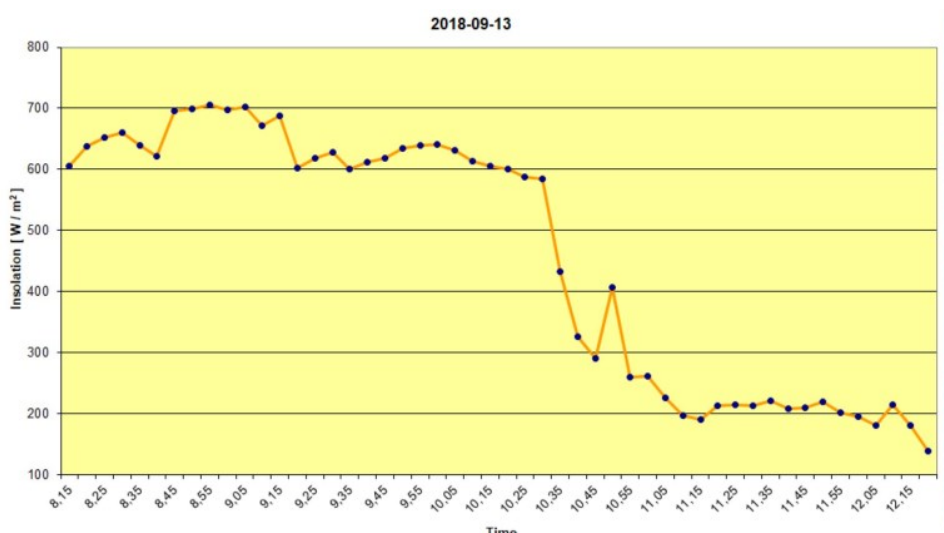

(a)

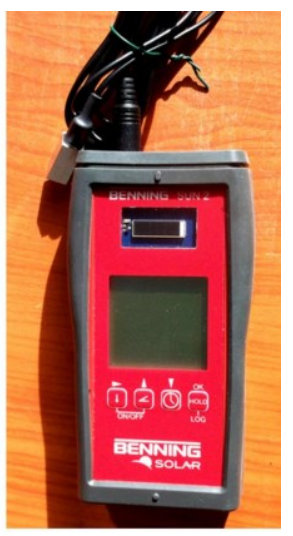

(b)

Fig. 5. Sunlight tests were carried out on being build in GIG PV panels for rail noise barriers test stand (a) and used solar meter (b)

Fig.5 presents an example of records obtained with the help of solar meter during sunlight tests, which were carried out on being built in GIG PV panel test stand. The tests for needs of South-North orientation of rail noise barrier with PV panels were performed.

\section{Summary}

Analysis of regulations and standards concerning noise road and rail barriers demonstrates that there are possible effective their tests for their short installations restricted to even two panels of length $2 \mathrm{~m}$ each and heigh $4 \mathrm{~m}$. This will be final test stands in the field foreseen within international CEFRABID research project, realised within ERA-SOLAR.NET European program, and concerning photovoltaic road and rail noise barriers for Austria, Cyprus, Poland and Spain, at different environmental and soil 
conditions, including mining terrains. They will be established and tested after initially labolatory tests and necessary designing and development works.

\section{References}

1. Bendtsen Hans, Final Report: Highway Noise Abatement: Planning Tools and Danish Examples, The Danish Road Institute, Reprint Report No UCPRC-RP-2010-03, 2010.

2. Noise management and abatement, Report of the Conference of European Directors of Roads (CEDR), April 2010.

3. EN 1793-1:2017 Road traffic noise reducing devices - Test method for determining the acoustic performance - Part 1: Intrinsic characteristics of sound absorption.

4. EN 1793-2:2018 Road traffic noise reducing devices - Test method for determining the acoustic performance - Part 2: Intrinsic characteristics of airbome sound insulation.

5. EN 1793-3:2001 Road traffic noise reducing devices - Test method for determining the acoustic performance - Part 3: Normalized traffic noise spectrum.

6. EN 1793-4:2015 Road traffic noise reducing devices - Test method for determining the acoustic performance - Part 4: Intrinsic characteristics - In situ values of sound diffraction.

7. EN 1793-5:2016 Road traffic noise reducing devices - Test method for determining the acoustic performance - Part 5: Intrinsic characteristics - In situ values of sound reflection and airborne sound insulation.

8. EN 1794-1:2018 Road traffic noise reducing devices - Non-acoustic performance Part 1: Mechanical performance and stability requirements.

9. EN 1794-2:2011 Road traffic noise reducing devices - Non-acoustic performance Part 2: General safety and environmental requirements.

10. EN 14388:2015 Road traffic noise reducing devices - Specifications.

11. EN 14389-1:2015 Road traffic noise reducing devices - Procedure for assessing long term performance - Part 1: Acoustical characteristics.

12. EN 14389-2:2015 - Road traffic noise reducing devices - Procedures for assessing long term performance - Part 2: Non-acoustical characteristics.

13. The Highway Agency. Design Manual for roads and bridges. Volume 10 Environmental Design and Management. Section 5 Environmental Barriers. Part 2. HA 66/95. Environmental Barriers: Technical Requirements.

14. Policy Department B (Structural and Cohesion Policies) of Directorate General for Internal Policies. Transport and Tourism Reducing Railway Noise Pollution - Study. Brussels, European Union, 2012.

15. Communication from the Commission to the European Parliament and the Council Rail noise abatement measures addressing the existing fleet. COM (2008) 432 final, Brussels, 8.7.2008.

16. Working Group Railway Noise of the European Commission: Position Paper on the European strategies and priorities for railway noise abatement, European Communities, Luxembourg 2003.

17. STAIRRS project in the 5th framework programme supported by the European Commission's Transport and Energy Directorate (2000-2002).

18. International Union of Railways (UIC): Noise Reduction in European Railway Infrastructure. Status Report 2007.

19. International Union of Railways (UIC): Railway noise in Europe. A 2010 report on the state of the art. September 2010. 